\title{
DISCLAIMER
}

This report was prepared as an account of work sponsored by an agency of the United States Government. Neither the United States Government nor any agency thereof, nor any of their employees, makes any warranty, express or implied, or assumes any legal liability or responsibility for the accuracy, completeness, or usefulness of any information, apparatus, product, or process disclosed, or represents that its use would not infringe privately owned rights. Reference herein to any specific commercial product, process, or service by trade name, trademark, manufacturer, or otherwise does not necessarily constitute or imply its endorsement, recommendation, or favoring by the United States Government or any agency thereof. The views and opinions of authors expressed herein do not necessarily state or reflect those of the United States Government or any agency thereof.

Report No. MIT - ANP - TR - 026

\section{THE DEPENDENCE OF HUMAN RELIABILITY UPON TASK INFORMATION CONTENT}

\author{
by
}

E.M. Hermanson

M.W. Golay

September 1994

Department of Nuclear Engineering

Massachusetts Institute of Technology 


\section{DISCLAIMER}

Portions of this document may be illegible in electronic image products. Images are produced from the best available original document. 


\section{PROGRAM FOR \\ ADVANCED NUCLEAR POWER STUDIES}

MIT-ANP-TR REPORTS

MIT-ANP-TR-001 "The Role of Actinide Burning and the Integral Fast Reactor in the Future of Nuclear Power," W.R. Hollaway, L.M. Lidsky and M.M. Miller (December 1990).

MIT-ANP-TR-002 "Out-of-Core Thermionic Space Nuclear Reactors: Design and Control Considerations," M.G. Houts and D.D. Lanning (January 1991).

MIT-ANP-TR-003

"Passive Decay Heat Removal in Advanced Reactor Concepts," Vols I \& II, P. Hejzlar, N.E. Todreas and M.J. Driscoll (May 1991).

MIT-ANP-TR-004

"The Effects of Non-Condensable Gases on Steam Condensation under Turbulent Natural Convection Conditions," A.A. Dehbi, M.W. Golay and M.S. Kazimi (June 1991).

MIT-ANP-TR-005

"The Effect of Thermal Conductivity of Prismatic MHTGR Fuel," J-C. Han, M.J. Driscoll, N.E. Todreas (September 1989).

MIT-ANP-TR-006

"Passive Containment Cooling for a 900 MWe Reactor," A.A. Dhebi, M.W. Golay and M.S. Kazimi (August 1991).

MIT-ANP-TR-007

"The Combined Hybrid System - A Symbiotic Thermal Reactor/Fast Reactor System for Power Generation and Radioactive Waste Toxicity Reduction," W.R. Hollaway and L.M. Lidsky (August 1991).

MIT-ANP-TR-008

"Concepts for a Pressure Tube Light Water Reactor with Passive Safety Features," J.R. Tang, N.E. Todreas and M.J. Driscoll (September 1991).

MIT-ANP-TR-009

MIT-ANP-TR-010

"Physics Considerations in a Passive Light Water Pressure Tube Reactor (PLPTR)," J.R. Tang, M.J. Driscoll and N.E. Todreas (November 1991).

"The Effects of Noncondensable Gases on Steam Condensation under Forced Convection Conditions, M. Siddique, M.W. Golay and M.S. Kazimi (March 1992).

MIT-ANP-TR-011 "A Sensitivity Analysis of the Role of Human Actions for the Loss of Offsite Power Scenario," N.S. Qureshi and M.W. Golay (May 1992).

MIT-ANP-TR-012

"ORNL/MIT Technical Support Tasks for USDOE/MITNE Integral Fast Reactor Program; Task 2, Environmental Impact Assessment," W.W. Schenler, M.W. Golay (May 1992).

MIT-ANP-TR-013 "Conceptual Design of the Passive Light Water Cooled and Moderated Pressure Tube Reactor (PLPTR)," Volumes 1 and 2, J.R. Tang, N.E. Todreas and M.J. Driscoll (August 1992).

MIT-ANP-TR-014 "Integral Fast Reactor-Related Research-Subtask 1C: Analysis of IFR Demonstration Program," Final Report, A. Schneider and D. Freed (June 1992). 
MIT-ANP-TR REPORTS (continued)

MIT-ANP-TR-015 "Transmutation Effects on Transuranic Waste Inventory and Its Repository Risk," C.H. Kang and M.S. Kazimi (March 1993).

MIT-ANP-TR-016 "Conceptual Design of a Water Cooled Reactor with Passive Decay Heat Removal," Progress Report to DOE, P. Hejzlar, N.E. Todreas, M.J. Driscoll and B. Mattingly (May 1993).

MIT-ANP-TR-017 "Evaluation of Materials for the Pressure Tube Matrix of a Passive LWR Concept," P. Hejzlar, N.E. Todreas and M.J. Driscoll (November 1993).

MIT-A.NP-TR-018 "An Evaluation of Passive Spray Cooling for Nuclear Reactor Containments," H. Khan and M.J. Driscoll (September 1993).

MIT-ANP-TR-019 "On the Complete Testing of Simple, Safety-Related Software," K.E. Poorman, M.W. Golay, D.D. Lanning (February 1994).

MIT-ANP-TR-020 "Integrated Containment/Hyperbolic Cooling Tower System," A.R. Patel, N.E. Todreas and M.J. Driscoll (January 1994).

MIT-ANP-TR-021 "Special Computer Codes and Supplementary Data for the Conceptual Design of a Large, Passive, Pressure-tube LWR," P. Hejzlar, N.E. Todreas and M.J. Driscoll (May 1994).

MIT-ANP-TR-022 "Verification and Validation of Safety Related Software, " M.G. Amo and M.W. Golay (June 1994).

MIT-ANP-TR-023 "Conceptual Design of a Large, Passive Pressure-Tube Light Water Reactor," P. Hejzlar, N.E. Todreas and M.J. Driscoll (June 1994).

MIT-ANP-TR-024 "Steam Condensation in the Presence of Noncondensable Gases under Forced Convection Conditions," H.A. Hasanein, M.W. Golay and M.S. Kazimi (July 1994).

MIT-ANP-TR-025 "Technical Summary of a Conceptual Design of a Large, Passive Pressure-Tube Light Water Reactor," P. Hejzlar, N.E. Todreas and M.J. Driscoll (July 1994).

MIT-ANP-TR-026 "The Dependence of Human Reliability Upon Task Information Content," E.M. Hermanson and M.W. Golay (August 1994). 


\section{OTHER RELEVANT REPORTS}

MITNPI-TR-035 "Dynamic Analysis and Control System Design for an Advanced Nuclear Gas Turbine Power Plant," X-L. Yan and L.M. Lidsky (May 1990).

MITNPI-TR-038, "Experimental and Analytic Evaluation of Gas-Cooled Reactor Cavity

Rev. 1 Cooling Systems," Rev. 1, G. Fu, M. Gavrilas, P. Hejzlar, M.J. Driscoll, N.E. Todreas (December 1991).

MITNPI-TR-039 "Numerical Calculation of Mixed Convection in a Duct under MHTGR Conditions," S. Yesilyurt, M.J. Driscoll and N.E. Todreas (June 1991).

MITNPI-TR-040 "MTR-TTI: An Indirect Closed Cycle MGR Gas Turbine Power Plant for Near-Term Deployment," X-L. Yan and L.M. Lidsky (August 1991).

MITNPI-TR-041 "Effects of Variation in Operational and Geometric Parameters on the Performance of the Gas-cooled Reactor Cavity Cooling System," M. Gavrilas, M.J. Driscoll, N.E. Todreas and P. Hejzlar (August 1992). 


\begin{abstract}
The role of human error in safety mishaps is an important factor in system design. As systems become increasingly complex the capacity of the human to deal with the added complexity is diminished. It is therefore crucial to understand the relationship between system complexity and human reliability so that systems may be built in such a way as to minimize human error. One way of understanding this relationship is to quantify system complexity and then measure the human reaction in response to situations of varying complexity. The quantification of system complexity may be performed by determining the information content present in the tasks that the human must execute. The purpose of this work is therefore to build and perform a consistent experiment which will determine the extent to which human reliability depends upon task information content.

Two main conclusions may be drawn from this work. The first is that human reliability depends upon task information content. Specifically, as the information content contained in a task increases, the capacity of a human to deal successfully with the task decreases monotonically. Here the definition of total success is the ability to complete the task at hand fully and correctly. Furthermore, there exists a value of information content below which a human can deal with the task successfully, but above which the success of an individual decreases monotonically with increasing information. These ideas should be generalizable to any model where system complexity can be clearly and consistently defined.
\end{abstract}




\section{ACKNOWLEDGEMENTS}

The author would like to acknowledge the generosity of the sponsors, The United States Department of Energy and M.I.T. Special thanks go to Matthew Schuetze, a colleague who volunteered his time to help beta test the software used in the research experiments. This report is based on work done by Eric M. Hermanson in fulfilling requirements for the Master of Science degree in the Nuclear Engineering Department at M.I.T. 


\section{TABLE OF CONTENTS}

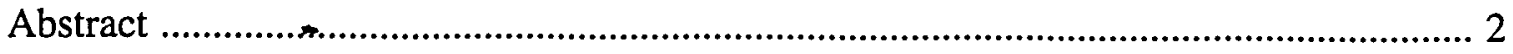

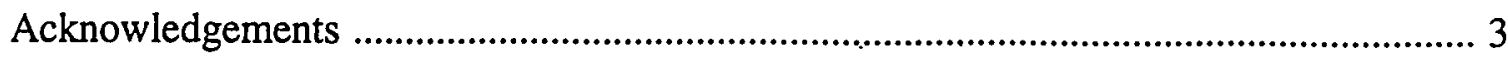

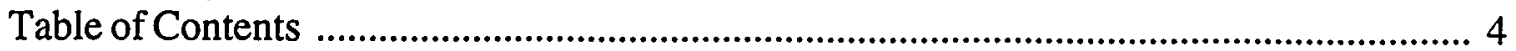

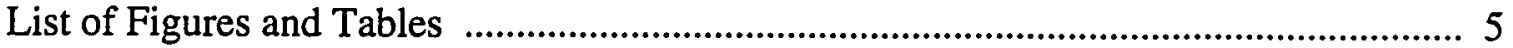

\section{Chapter 1}

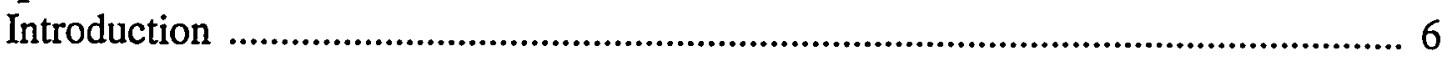

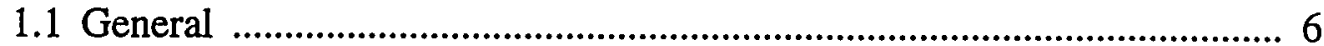

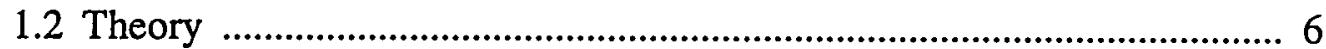

1.2.1 Background .................................................................. 7

1.2.2 Literature Survey ............................................................. 8

1.3 Method of Investigation .............................................................. 10

\section{Chapter 2}

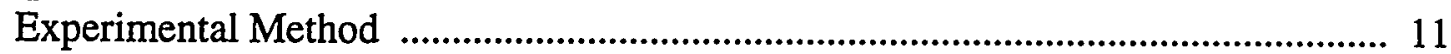

2.1 Experimental Plan and Design Motivation .......................................... 11

2.2 Description of Physical System Modeled ......................................... 12

2.3 Training of the Subjects ............................................................... 16

2.4 Determination of Information Content ............................................ 17

2.4.1 Neutron Source Perturbation .............................................. 20

2.4.2 Valve Blockage ............................................................. 21

2.4.3 Steam Generator Leak .................................................. 21

2.4.4 Special Situations ........................................................ 23

\section{Chapter 3}

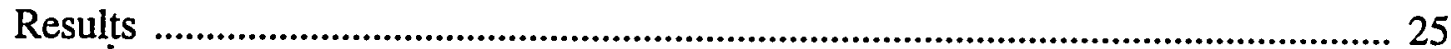

3.1 Experimental Results …............................................................. 25

3.2 Discussion of Experimental Error .................................................. 34

\section{Chapter 4}

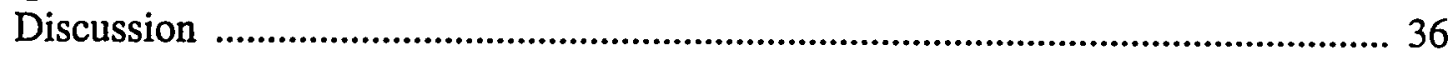

\section{Chapter 5}

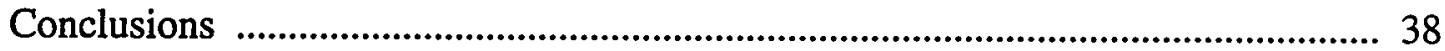

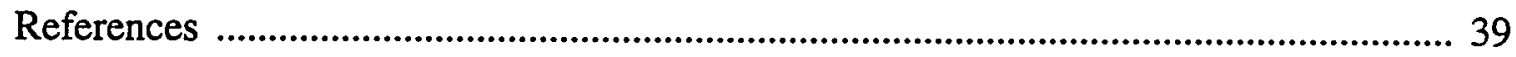

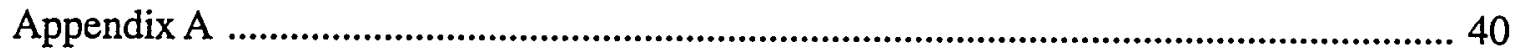

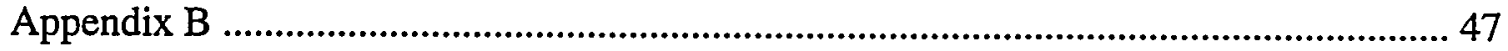




\section{LIST OF FIGURES AND TABLES}

In Order of Appearance

Type \& No.

Figure 2-1

Figure 2-2

Table 2-1

Table 2-2

Table 3-1

Figure 3-1

Table 3-2

Figure 3-2

Table 3-3

Figure 3-3

Table B-1

Table B-2
Description

Schematic Diagram of the Modeled System

Image of the Simulation's Graphical Interface

Perturbation Table for Experiment Set \#1

Perturbation Table for Experiment Set \#2

Summary of Results Obtained from Experiment Set \#1

Graph of Human Reliability vs. Values of Information

Content Assigned in Experiment Set \#1

Summary of Results Obtained from Experiment Set \#2

Graph of Human Reliability vs. Values of Information

Content Assigned in Experiment Set \#2

Summary of Results Combined Over Both Experiments $\quad 32$

Graph of the Combined Results Indicating Relationship 33

Between Human Reliability and Task Information Content

Complete Listing of Experimental Data from Set \#1

Complete Listing of Experimental Data from Set \#2
Page

13

15

18

19

26

27

29

30

33 48

49 


\section{Chapter 1}

\section{Introduction}

\subsection{General}

The role of human error in safety mishaps is an important factor in system design. As systems become increasingly complex the capacity of the human to deal with the added complexity is diminished. It is therefore crucial to understand the relationship between system complexity and human reliability so that systems may be built in such a way as to minimize human error. One way of understanding this relationship is to quantify system complexity and then measure the human reaction in response to situations of varying complexity. The quantification of system complexity may be performed by determining the information content present in the tasks that the human must execute. The purpose of this work is therefore to build and perform a consistent experiment which will determine the extent to which human reliability depends upon task information content.

\subsection{Theory}

This section serves to motivate the theory behind the work reported here. A brief literature search is also included to indicate the foundation upon which this work was born. 


\subsubsection{Background}

Researchers have taken advantage of the idea that information measures uncertainty according to information theory. Highly certain events do not contain much information since they are expected in the first place. Highly unlikely events, however, contain more information because their appearance occurs despite an abundance of alternative outcomes [1]. For example, a fire alarm that is tested once a week at noon on Friday will be expected to ring at that time every week, regardless of whether there is a fire or not. So this alarm conveys only that it is operating; we can not determine whether there is an actual fire, or whether it is truly a test. However, if the alarm rings unexpectedly at $3 \mathrm{pm}$ on Thursday, more information is conveyed by this unexpected event since it is likely that the alarm does not indicate a test, and instead it indicates an actual fire.

With the concept of information defined, we can offer the mathematical basis for information theory. Information theory defines information content as

$$
H=-\sum_{i=1}^{n} p_{i} \log _{2}\left(p_{i}\right)
$$

where $\mathrm{H}$ is the information content, $\mathrm{n}$ is the number of system states, and $\mathrm{p}_{\mathrm{i}}$ is the probability of occurrence of the $i_{\text {th }}$ state. The information content is conventionally measured in terms of 'bits', where one bit is the amount of information required to distinguish between two different states. If the probability of the states are equal we have the maximum amount of informational entropy (termed the information content in 
this work) available to us with $\mathrm{H}$ defined as

$$
H=\log _{2} N
$$

Here $\mathrm{N}$ is the average number of interrogations needed to determine which state the system lies in. It has been shown that the information content is a useful measure of the complexity of a system [2]. Additionally, it was shown that the information content is a useful measure of the difficulty of diagnosing the true state of a system. In the work reported here, the goal is for the subject to diagnose what state a system is in after it is put into a random state. We will therefore use equation 1.2 as a basis for our definition of information content.

\subsubsection{Literature Survey}

Literature explicitly concerning the dependence of human reliability upon system complexity is rare. Most existing literature concerns itself with information theory in the context of communication engineering, the field where information theory was born during the 1940s. It was not until the early 1950s when the connection between information theory and cognitive psychology took place. This connection allowed information theory, which had previously been used in computer communication studies, to be used as a basis for cognitive processing studies. .The first of these studies involved measuring the choice reaction time of an individual to a random stimulus [3]. In this study Hick varied the number of visual stimuli (flashing lights) while asking subjects to 
push certain buttons to indicate which lights had flashed. The reaction time of the individuals was measured and it was found that reaction time to a stimulus increased linearly as the number of flashing lights increased. In other words, the reaction time of the individuals was found to increase as the complexity of the situation increased. A year later Hyman extended the work of Hick by altering the probability of occurrence of the visual stimuli instead of altering the number of visual stimuli [4]. His results were identical to Hick's even though he went about things in a different manner. Hyman's findings served to generalize Hick's conclusions that reaction time was a linear function of stimulus information. A new principle was born, and it was termed the Hick-Hyman Law. Equation 1.1 represents the generalized law, while equation 1.2 represents the more specific conclusions that Hick initially came to by assuming that the states of the system had identical probabilities of occurring.

More recent work concentrates on applying the Hick-Hyman Law to physical systems. Seong et. al. used information theory to develop a methodology for creating designs which are efficient to diagnose. They utilized the example of the condensate feedwater system in a nuclear power plant [5]. The work involved networking pumps and valves into a system and calculating the information content present in the resulting arrangement. The goal was to minimize human error in diagnosing a system with failed components by keeping system complexity to a minimum while assuring an efficient physical design at minimal cost. Studies performed by Rouse and Rouse [6], and Golay et. al. [2], also explore the difficulty of diagnosing a system with failed components. These works each use their own information theoretic measures to show that the number 
of interrogations needed to diagnose the condition of a failed system increases monotonically with the information content of the system. The success of these studies motivated us to simplify the problem and study in greater depth the fundamental relationship between human reliability and task information content. However, the work reported here attempts to go one step beyond this relationship by building off of the results from a separate study by Mackinnon and Wearing [7]. This study infers that there may exist a value of information content below which a human can ideally perform the task asked of them. This leads one to suspect that human reliability may be independent of information content at low levels of system complexity where tasks are exceptionally simple to perform. Once this threshold value of information is surpassed, however, one expects to see a degradation in human performance as system complexity increases.

\subsection{Method of Investigation}

There are two aspects to the work reported here. The first task is the design and implementation of a computer simulation that will measure the relationship between human reliability and task information content by requiring a human subject to diagnose failed systems of varying complexity. This part of the work includes defining the physical system to be modeled, training the research subjects, and assuring that the information content present in the computer simulations is clearly defined. The second task consists of analyzing the data and coming to useful conclusions about the relationship between human reliability and task information content. 


\section{Chapter 2}

\section{Experimental Method}

\subsection{Experimental Plan and Design Motivation}

The motivation for the design of the computer simulation lies in the fact that we needed to measure human reliability in the light of differing amounts of task information content. Our aim was to create an interactive simulation that would adhere to the following goals.

- We wished to model a physical system where the data can be generalized beyond the scope of the model.

Since an important application requiring high human reliability lies in nuclear power related areas, we chose to create a two loop nuclear power plant simulation as defined in Section 2.2. Since our model conveys information in a consistent and clearly defined way, it should be possible to extend our results to a more fundamental level of generality as is discussed in Chapter 4.

- The simulation must allow a simple but precise way to vary task information content.

The nuclear power plant model is a valuable system which allows a great deal of flexibility in creating situations of varying complexity. The final section of this chapter 
explains how perturbations in the simulated system were used to allow specific amounts of information to be displayed to the research subject.

With these goals in mind, we can summarize the substance of the experiments. During the simulations, research subjects are asked to perform tasks containing differing amounts of information. Specifically, the information content contained in a computer experiment refers to the number and kind of nuclear reactor perturbations introduced during the computer simulation. Based upon the human responses to this information, it is hypothesized that a specific pattern of behavior will be observed. The hypothesis to be tested is that as the information content present in a task increases past a certain threshold value, the task will become more complex and will require an increasing amount of time to complete. In more specific terms, with this model the success of an individual in completing a task will decline monotonically as the information content manifested in the task increases past a certain threshold value..

The following sections describe the implementation of the experiment reported here.

First, the physical system modeled in the computer simulation is discussed, followed by a definition of the subject training, and then an explanation of the information content of the experiments.

\subsection{Description of Physical System Modeled}

This section describes the physical system that was modeled in the computer 
simulation. The model was built with simplicity in mind.

The system modeled in a simulation consists of two steam generators connected in parallel to a reactor core. Each steam generator loop contains both a valve and pump which together control the mass flow rate of coolant flowing through each steam generator. In addition, each steam generator transfers heat to a colder fluid across the tube walls of a heat exchanger element located in the generator. Refer to Figure 2-1 for a schematic illustration of the system.

\section{Figure 2-1}

Schematic Diagram of the Modeled System

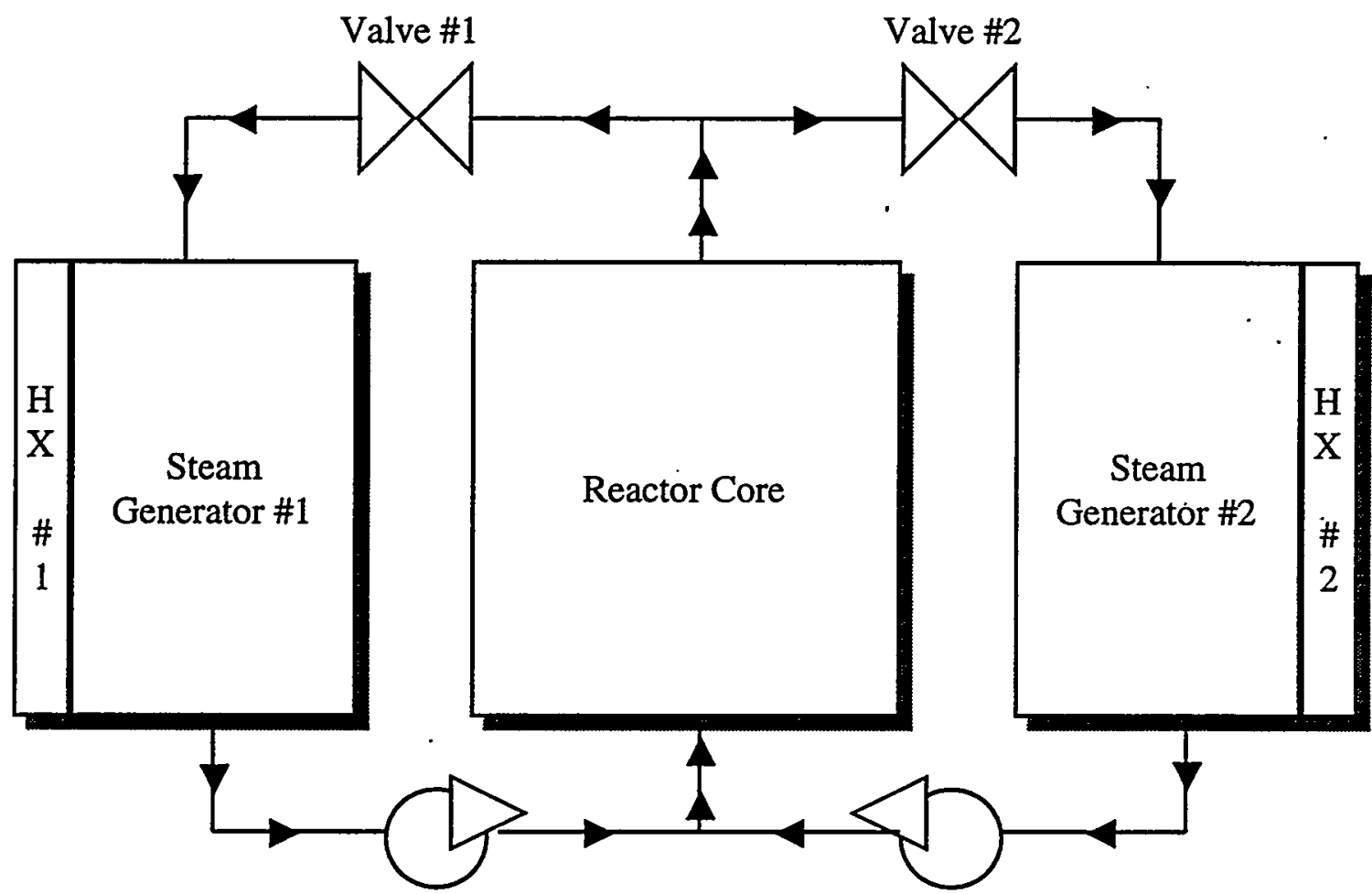

Pump \#1

Pump \#2 
The system user has the ability to control the valve status, the pump pressure, and the heat exchange rate in each steam generator loop. This is done by moving the slider corresponding to each independent control on the computer user interface. The interface is a 17-inch diagonal color monitor (CRT). The user may also control the neutron population in the core, which has a direct effect on the reactor power. This is done by moving a slider which represents the average height of all the control rods within the core. The neutronic behavior is governed by the point neutron kinetics equations [8], while the heat and mass transfer of the coolant fluid is governed by one-dimensional, incompressible thermal hydraulic theory [9]. See Appendix A for more information about the governing equations.

This system manifests six dependent variables which reflect the status of the simulation. Four of the six variables (the mass flow rate in each steam generator, the average core temperature, and the power) are displayed to the user through both numerical gauges and graphical lines on the CRT screen. The gauges which display the corresponding instantaneous numerical values are located above the graph. The remaining two dependent variables (the outlet temperature of each steam generator) are displayed solely via gauges located above the graph. See Figure 2-2 for a screen view of the user interface to the simulation. 
Figure 2-2

Image of the Simulation's Graphical Interface

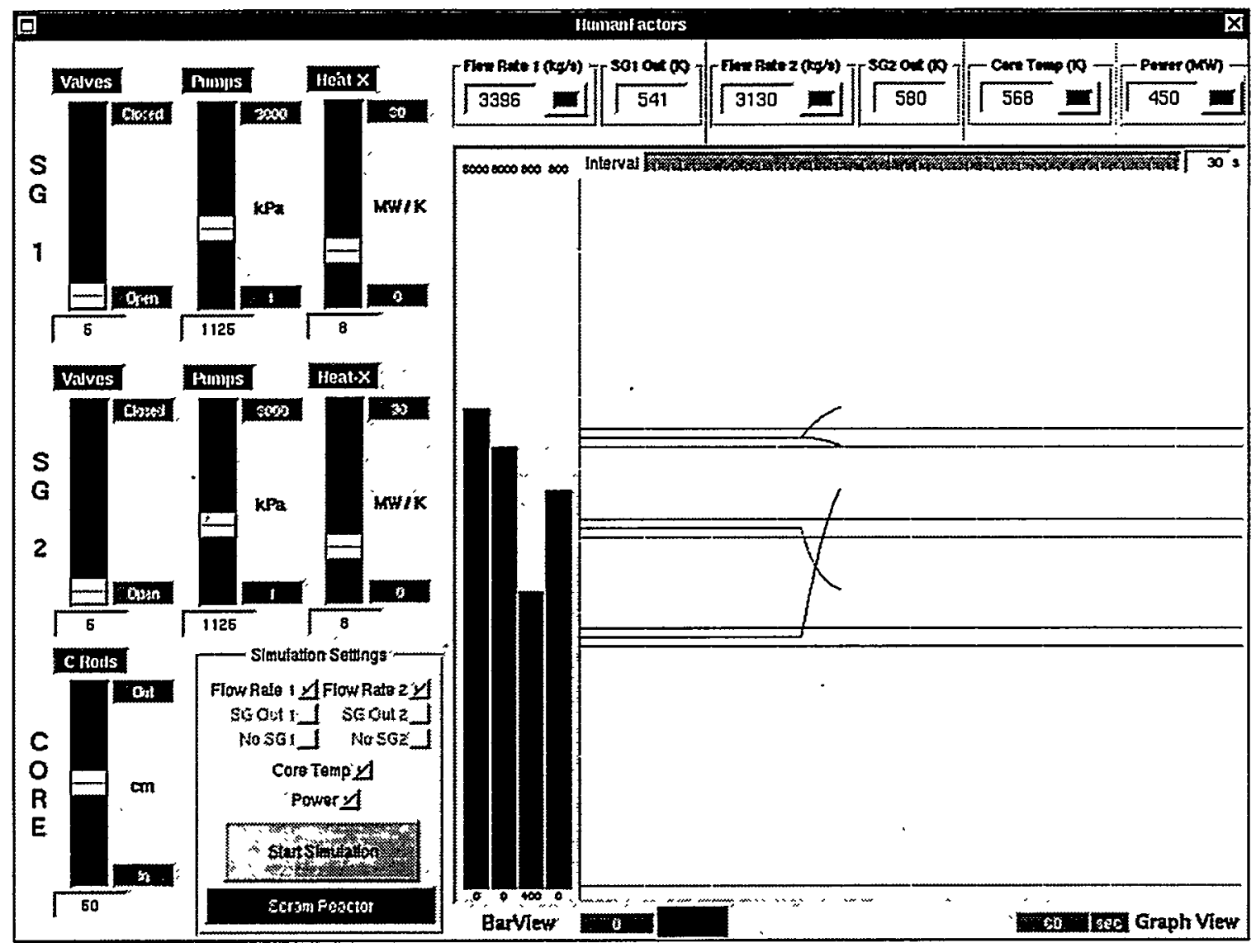




\subsection{Training of the Subjects}

For the initial phase of the research, M.I.T. Nuclear Engineering Department students were recruited to participate in the computer simulation. The pool of subjects was limited to this specific group in order to simplify the selection process while assuring that the students selected would be somewhat familiar with nuclear power systems. Sixteen students participated.

All subjects were consistently trained to identify the planned system perturbations and to fix them. During the experiment, one or more perturbations were caused to occur at random, which caused the dependent variables to depart from their initial positions. The subject was required to analyze the perturbation(s) and diagnose what type of disturbance had occurred in order to fix things properly. To "repair" the perturbation(s), the subject was trained to manipulate the valves, pumps, heat exchangers, and control rods in such a way as to return the dependent variables back within the vicinity of their equilibrium values. The user was asked to fix either the mass flow rates, the core temperature, the power, or any combination of the three. The corresponding equilibrium range boundaries automatically showed up on the graph to indicate to the user which variables were to be controlled for that particular experiment.

The subjects were run through multiple sets of training experiments where they practiced fixing each specific perturbation according to an invariable set of rules that reflected the best way to go about returning to the equilibrium state. They were trained until they were able to fix each perturbation proficiently, and until they were able to fix 
the perturbations reliably. This had the effect that the information content of the formal experiments lay solely in the process of identifying the perturbations. The perturbations were always introduced at ten seconds into the 90 second simulations. This point is discussed further in the next section.

\subsection{Determination of Information Content}

This section describes how the perturbations introduced into the simulation determine the information content of the experiments. Each perturbation, as well as a set of special circumstances, is explained separately.

As is mentioned in the previous section, in the actual experiments, once the user was able to identify which perturbations had occurred, their training allowed them to fix what had gone wrong. Therefore, the number of questions that had to be answered in order to diagnose which perturbations had actually occurred was directly related to the information content of a particular experimental trial. As more perturbations occurred in an experiment the information content increased steadily, and more time was required for the subject to fix those perturbations.

There were three types of perturbations presented to the subjects in the experiments. Tables 2-1 and 2-2, respectively, show the perturbations given for the two sets of experiments that were run. 
Table 2-1

Perturbation Table for Experiment Set \#1

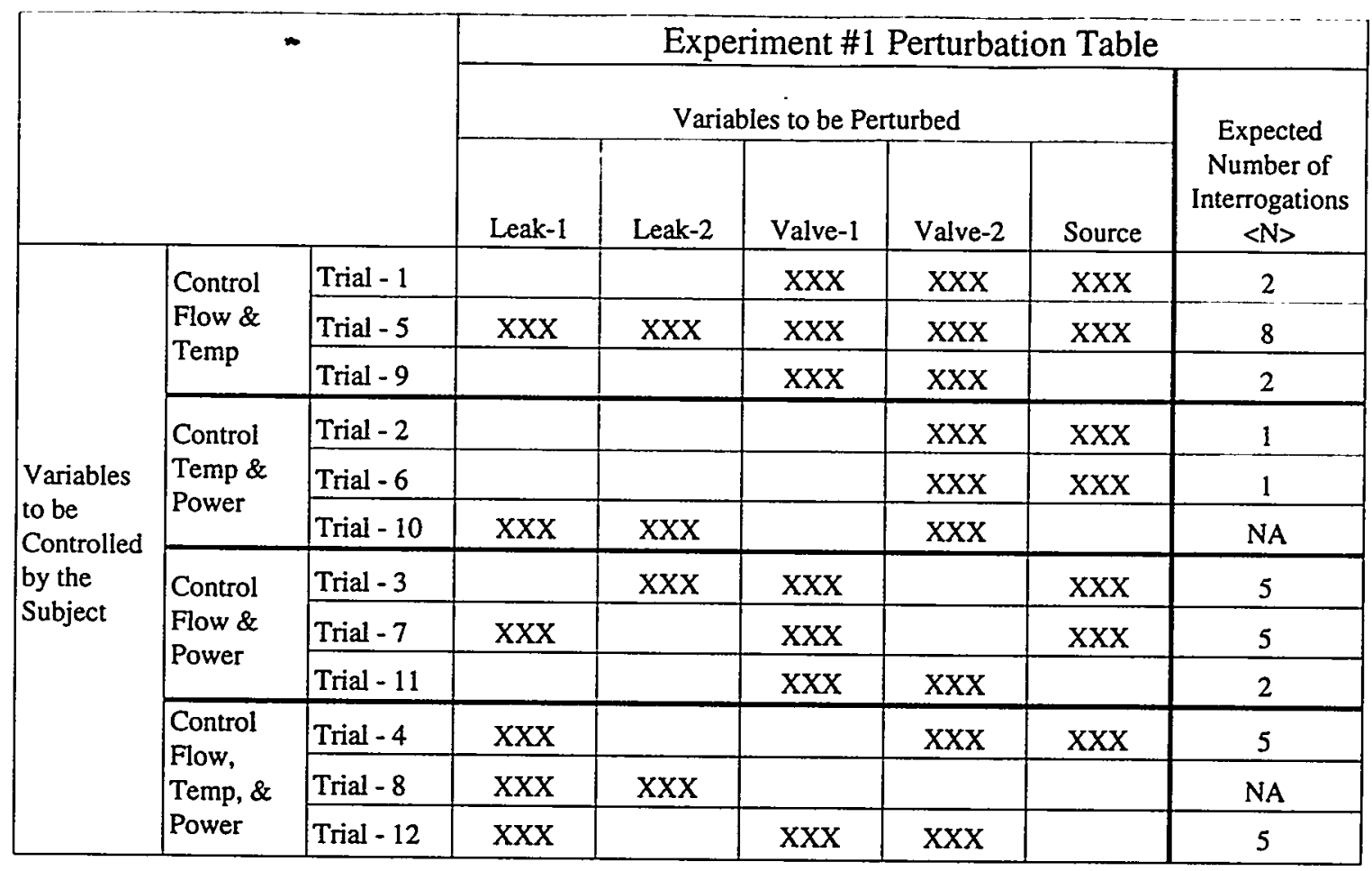

Note: $N A=$ Not Applicable 
Table 2-2

Perturbation Table for Experiment Set \#2

\begin{tabular}{|c|c|c|c|c|c|c|c|c|}
\hline \multirow{3}{*}{\multicolumn{3}{|c|}{. }} & \multicolumn{6}{|c|}{ Experiment \#2 Perturbation Table } \\
\hline & & & \multicolumn{5}{|c|}{ Variables to be Perturbed } & \multirow{2}{*}{$\begin{array}{c}\text { Expected } \\
\text { Number of } \\
\text { Interrogations } \\
<\mathrm{N}\rangle \\
\end{array}$} \\
\hline & & & Leak-1 & Leak-2 & Valve-1 & Valve-2 & Source & \\
\hline \multirow{12}{*}{$\begin{array}{l}\text { Variables } \\
\text { to be } \\
\text { Controlled } \\
\text { by the } \\
\text { Subject }\end{array}$} & \multirow{3}{*}{$\begin{array}{l}\text { Control } \\
\text { Flow \& } \\
\text { Temp }\end{array}$} & Trial - 1 & & & & $\mathrm{XXX}$ & & 1 \\
\hline & & Trial - 5 & $\mathrm{XXX}$ & & $\mathrm{XXX}$ & & & 3 \\
\hline & & Trial - 9 & & & $\mathrm{xxx}$ & $\mathrm{XXX}$ & & 2 \\
\hline & \multirow{3}{*}{$\begin{array}{l}\text { Control } \\
\text { Temp \& } \\
\text { Power }\end{array}$} & Trial - 2 & $\mathrm{XXX}$ & $\mathrm{XXX}$ & & & & NA \\
\hline & & Trial - 6 & & $\mathrm{XXX}$ & & & $\mathrm{xxx}$ & 3 \\
\hline & & Trial -10 & $\mathrm{XXX}$ & & & & & 2 \\
\hline & \multirow{3}{*}{$\begin{array}{l}\text { Control } \\
\text { Flow \& } \\
\text { Power }\end{array}$} & Trial - 3 & & $\mathrm{XXX}$ & $\mathrm{XXX}$ & $\mathrm{XXX}$ & $\mathrm{xXX}$ & 5 \\
\hline & & Trial -7 & $\mathrm{xxX}$ & $\mathrm{XXX}$ & $\mathrm{XXX}$ & $\mathrm{XxX}$ & $\mathrm{XXX}$ & 6 \\
\hline & & Trial - 11 & & & $\mathrm{XXX}$ & $\mathrm{XXX}$ & $\mathrm{XXX}$ & 3 \\
\hline & \multirow{3}{*}{$\begin{array}{l}\text { Control } \\
\text { Flow, } \\
\text { Temp, \& } \\
\text { Power }\end{array}$} & Trial -4 & $\mathrm{xxx}$ & & & $\mathrm{XXX}$ & & 3 \\
\hline & & Trial - 8 & & $\mathrm{XXX}$ & $\mathrm{XXX}$ & $\mathrm{xxx}$ & $\mathrm{xxx}$ & 5 \\
\hline & & Trial - 12 & & & $\mathrm{XXX}$ & & $\mathrm{xxX}$ & 2 \\
\hline
\end{tabular}




\section{Note: $N A=$ Not Applicable}

The order of the sets of perturbations was selected at random to fill the tables with one set of subjects being given the perturbations in the first table, and a second set of subjects being given the perturbations in the second table. The difference between the two separate sets of experiments is explained further in Section 2.4.3. The symbol 'XXX' on a table indicates which perturbations were presented for a specific trial. Each type of perturbation was rated (as is explained in the following sections of this chapter) and given a value which represented the expected number of interrogations needed to identify it. Therefore, the information content of a particular experimental trial, as is defined in Section 1.2, was calculated as the $\log$ of the sum of the expected number of interrogations needed to identify the perturbations present in that experiment. The last column in the tables indicates this sum.

What follows is a detailed description of the perturbations introduced in the trials and how those perturbations contribute to the information content (or number of interrogations) contained in the experimental trials.

\subsubsection{Neutron Source Perturbation}

With this perturbation the reactor core is exposed to an external source of neutrons which causes the neutron population within the core to rise, thereby causing power to rise along with it. This is evident to the operator because the power level graph is seen to rise. This is the only effect of the neutron source term. This perturbation requires one (1) 
interrogation in order to be diagnosed properly because a rise in the power level that is not accompanied by any other visible changes in the system can only be caused by a neutron source perturbation for the system modeled in this work. Therefore the subject has enough information after one interrogation to determine the cause of the perturbation. The power level is restored to a steady level by lowering the control rods into the core to absorb the extra neutrons introduced by the source.

\subsubsection{Valve Blockage}

In the valve blockage perturbation either of the two valves which, respectively, control the coolant flow to the two steam generators may become obstructed such that the mass flow rate of coolant through the respective steam generator is reduced. This is manifested to the user by a drop in the mass flow rate graph. This perturbation also requires one (1) interrogation by the subject in order to be diagnosed properly because a valve blockage is the only perturbation that will cause a drop in the mass flow rate. Therefore a single interrogation will be sufficient to determine the state of the system. The perturbation is fixed by increasing the pump pressure in the loop that holds the obstructed valve.

\subsubsection{Steam Generator Leak}

A leak in the cold coolant piping of a steam generator causes a reduction of coolant pressure to occur in which the steam outlet temperature of the generator in question drops, subsequently causing the core temperature to drop. In addition, as a result of temperature feedback effects in the reactor core, the reactivity and therefore the power level increases for 
this perturbation. The user must identify two separate pieces of information to fix this type of perturbation. First, they must recognize that the core temperature drops while the power level increases in order to verify that a steam generator leak has occurred. Second, the subject must identify in which steam generator the leak has occurred. Therefore the user must analyze the steam generator outlet temperature gauges to determine for which generator the steam outlet temperature is abnormally low. This is an indication of where the leak has occurred. This perturbation therefore requires two (2) interrogations in order to be diagnosed properly. This is so because a leak is the only type of perturbation that causes changes in power and temperature simultaneously. Therefore a single interrogation determines that a leak has occurred, but a second interrogation is needed to confirm in which of the two steam generators the leak has manifested itself. The leak requires two interrogations in the second set of experimental trials (see Table 2-2). The subjects were trained to fix the perturbation by decreasing the rate of heat exchange in the steam generator having the leak, and by inserting the control rods into the core in order to bring the power level down.

In a separate set of experimental trials, the subjects were not told that they needed to insert the control rods in addition to decreasing the amount of heat exchange in order to fix the leak perturbation. An additional interrogation had to be performed in order to determine that the control rods also needed to be manipulated in order to fully respond to the leak. The need for this additional interrogation is similar to the neutron source perturbation case since the user has to determine that the power is unusually high, but it can still be distinguished from the source perturbation since the temperature is also changing. Therefore the leak 
perturbation in this case contained an additional problem that had to be solved (it contained additional information) requiring three (3) interrogations instead of two in order to be diagnosed properly. Occurrence of the leak requires three interrogations in the first set of experimental trials (see Table 2-1).

\subsubsection{Special Situations}

In addition to the above rules which govern determination of the information content of a task, there also exist special situations where the information content is determined by additional rules. Refer to Tables 2-1 and 2-2 for a description of the perturbations given in the experiments. The special situations are described below.

Source perturbations are meaningless when power is not being controlled. If the experiment does not call for the power to be controlled by the user (as indicated in Tables 2-1 and 2-2), then a source perturbation, which only has an upwards effect on the power, will not contribute to the task information content as far as controlling the reactor is concerned. Therefore, if a source perturbation occurs in this particular type of experiment, it will be ignored when determining task information content.

Valve perturbations are meaningless when flow rate is not being controlled. Just as in the case with the source perturbation, a valve perturbation is ignored when determining total information content in an experiment whenever mass flow rate is not one of the variables being controlled by the subject.

A leak in both steam generators when both power and temperature are being controlled results in an unstable simulation. These data points are ignored in the analysis of the results. 
If a double leak occurs (a simultaneous leak in both steam generators) the simulation becomes unstable because a leak affects both the power and the temperature. Since the perturbations were selected at random, on a few occasions a double leak occurred while the power and the temperature was being controlled. Because of the instability of the simulation, these data points were ignored, and they are represented by NA (not applicable) on the perturbation table.

The effect of a source perturbation is masked when this type of perturbation occurs along with a leak in both steam generators. Whenever a leak in both steam generators occurs (and either power or temperature is being controlled) the leak perturbation has a much more profound upwards effect on the power than the source perturbation does and so the source perturbation can safely be ignored in this situation. The task information content therefore does not include the information due to the source perturbation in this type of situation. 


\section{Chapter 3}

\section{Results}

The results obtained from this work are summarized in this section. A discussion of the possible sources of experimental error is also offered.

\subsection{Experimental Results}

The averaged data obtained from the first set of experiments is shown in Table 3-1. The numbers that head the columns are a measure of the information content for the six rows of data that follow. The first row in the table indicates the average amount of time required for the research subjects to return the dependent variables back to within their equilibrium ranges following the perturbation(s). Table B-1 in Appendix B shows the results of the individual experimental trials from which the averages in Table 3-1 are obtained. The remaining rows in Table 3-1 are self explanatory. The trend of the data is that at low information content the average time to return the system to equilibrium is short. As the information content that the subject has to deal with increases, the required time to establish equilibrium also increases, as is evidenced by Figure 3-1. 
Table 3-1

Summary of Results Obtained from Experiment Set \#1

\begin{tabular}{|c|c|c|c|c|c|c|c|c|}
\hline & \multicolumn{8}{|c|}{$\begin{array}{c}\text { Data From Experiment Set \#1 } \\
\end{array}$} \\
\hline & \multicolumn{8}{|c|}{ Expected Number of Interrogations Needed To Determine True State of System } \\
\hline & 1 & 2 & 3 & 4 & \begin{tabular}{|l|l|}
5 & -1 \\
\end{tabular} & 6 & 7 & 8 \\
\hline $\begin{array}{l}\text { Average Time } \\
\text { Required for } \\
\text { Success by the } \\
\text { Subjects (sec) }\end{array}$ & 17.8 & 26.5 & & . & 46.1 & & & 65.0 \\
\hline $\begin{array}{l}\text { Standard } \\
\text { Deviation of } \\
\text { Recorded Data }\end{array}$ & 3.9 & 3.8 & & & 7.3 & & & 4.3 \\
\hline $\begin{array}{l}\text { Variance of } \\
\text { Recorded Data }\end{array}$ & 15.6 & 14.1 & & & 52.9 & & & 18.8 \\
\hline $\begin{array}{l}\text { Number of } \\
\text { Trials } \\
\text { Performed }\end{array}$ & 13 & 19 & & $:$ & 22 & & & 21 \\
\hline
\end{tabular}


Figure 3-1

Graph of Human Reliability vs. Values of Information Content • Assigned in Experiment Set \#1

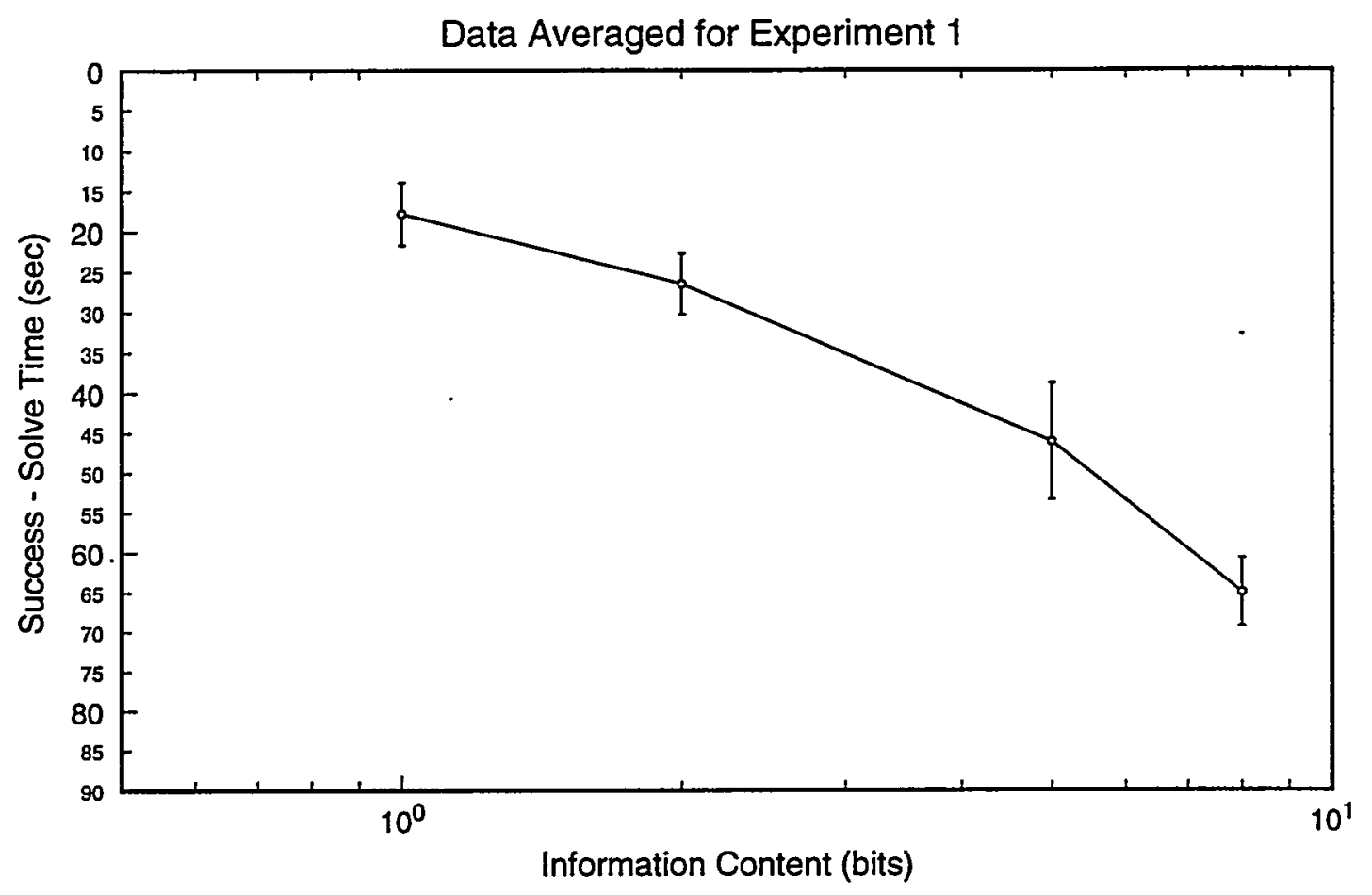


Note: The success, or solve time, plotted on the ordinate axis refers to the average time in seconds required for the research subjects to regain equilibrium control of the reactor during the experimental trials.

Note that the $\mathrm{x}$-axis in Figure 3-1 is logarithmic since information theory defines the amount of information in bits to be the log of the number of expected interrogations $\mathrm{N}$, as is explained in section 1.2. The success of a subject in an experiment was determined by the amount of time required for the subject to regain equilibrium control of the reactor. The definition of total success is the ability to fully and correctly complete the task at hand, and in this case, the task was to fix the perturbation(s) that had occurred. The subject was therefore less successful as the amount of time required to bring the variables back under control increased.

Table 3-2 shows the averaged numerical results for the second experiment, while Figure 3-2 displays those results graphically. Table B-2 in Appendix B shows the results of the individual experimental trials from which the averages in Table 3-2 are obtained. 
Table 3-2

Summary of Results Obtained

from Experiment Set \#2

\begin{tabular}{|c|c|c|c|c|c|c|c|c|}
\hline & \multicolumn{8}{|c|}{ Data From Experiment Set \#2 } \\
\hline & \multicolumn{8}{|c|}{ Expected Number of Interrogations Needed To Determine True State of System } \\
\hline & 1 & 2 & 3 & 4 & 5 & 6 & 7 & 8 \\
\hline $\begin{array}{l}\text { Average Time } \\
\text { Required for } \\
\text { Success by the } \\
\text { Subjects (sec) }\end{array}$ & 19.4 & 23.9 & 29.4 & & 43.8 & 51.3 & & \\
\hline $\begin{array}{l}\text { Standard } \\
\text { Deviation of } \\
\text { Recorded Data }\end{array}$ & 2.3 & 2.8 & 3.3 & & 2.8 & 4.5 & & \\
\hline $\begin{array}{l}\text { Variance of } \\
\text { Recorded Data }\end{array}$ & 5.4 & 8.1 & 10.9 & & 7.7 & 20.0 & & \\
\hline $\begin{array}{l}\text { Number of } \\
\text { Trials } \\
\text { Performed }\end{array}$ & 7.0 & 21.0 & 25.0 & & 13.0 & 21.0 & $\therefore$ & \\
\hline
\end{tabular}


Figure 3-2

Graph of Human Reliability vs. Values of Information Content

Assigned in Experiment Set \#2

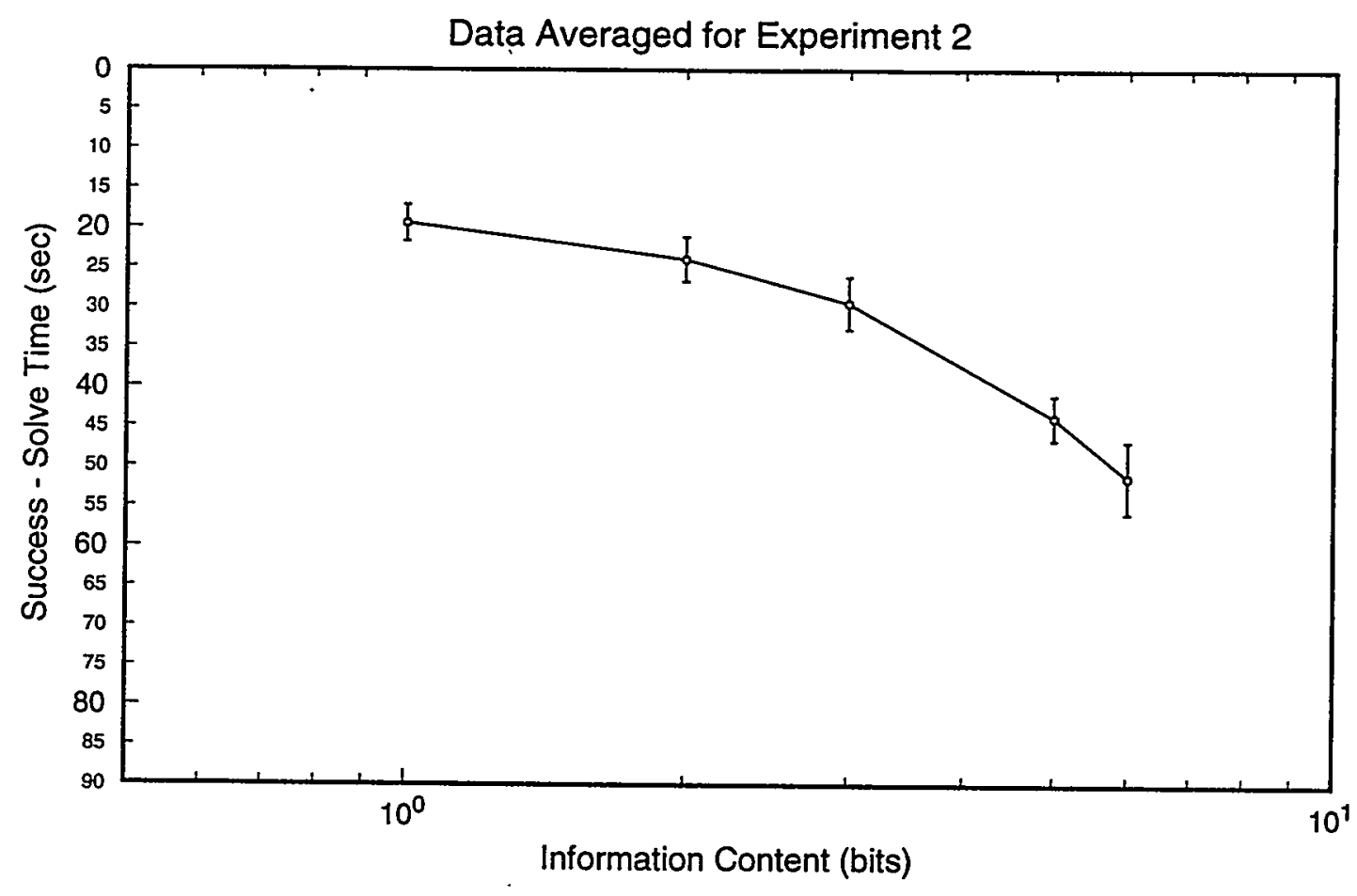


Note: The success, or solve time, plotted on the ordinate axis refers to the average time in seconds required for the research subjects to regain equilibrium control of the reactor during the experimental trials.

The trends are similar in the second set of experiments. Again, as the information content that the subject has to deal with increases, the required time to establish equilibrium also increases. However, in the second set of experiments a plateau like region in the data of the time interval required for success by the individuals is noticeable at low values of information content. The plateau appears to indicate a threshold value of information content below which the subject can deal successfully with the system, but above which the success of the individual decreases as the task information content increases.

We should be able to combine the data obtained in the two experiments since the information content is consistently defined in both sets of experiments. This gives us a clearer picture regarding how human reliability depends upon information content since gaps in the graphs of Figures 3-1 and 3-2 are filled in when the data is combined. Refer to Table 3-3 and Figure 3-3. 


\section{Table 3-3}

Summary of Results Combined Over Both Experiments

\begin{tabular}{|c|c|c|c|c|c|c|c|c|}
\hline & \multicolumn{8}{|c|}{ Data From Experiment Sets \#1 \& \#2 } \\
\hline & \multicolumn{8}{|c|}{ Expected Number of Interrogations Needed To Determine True State of System } \\
\hline & 1 & 2 & 3 & 4 & 5 & 6 & 7 & 8 \\
\hline $\begin{array}{l}\text { Average Time } \\
\text { Required for } \\
\text { Success by the } \\
\text { Subjects (sec) }\end{array}$ & 18.4 & 25.1 & 29.4 & & 45.3 & 51.3 & & 65.0 \\
\hline $\begin{array}{l}\text { Standard } \\
\text { Deviation of } \\
\text { Recorded Data }\end{array}$ & 3.6 & 3.6 & 3.3 & & 6.1 & 4.5 & & 4.3 \\
\hline $\begin{array}{l}\text { Variance of } \\
\text { Recorded Data }\end{array}$ & 12.6 & 12.6 & 10.9 & & 37.4 & 20.0 & & 18.8 \\
\hline \begin{tabular}{|l|} 
Number of \\
Trials \\
Performed \\
\end{tabular} & 20.0 & 40.0 & 25.0 & & 35.0 & 21.0 & & 21.0 \\
\hline
\end{tabular}




\section{Figure 3-3}

Graph of the Combined Results Indicating Relationship Between Human Reliability and Task Information Content

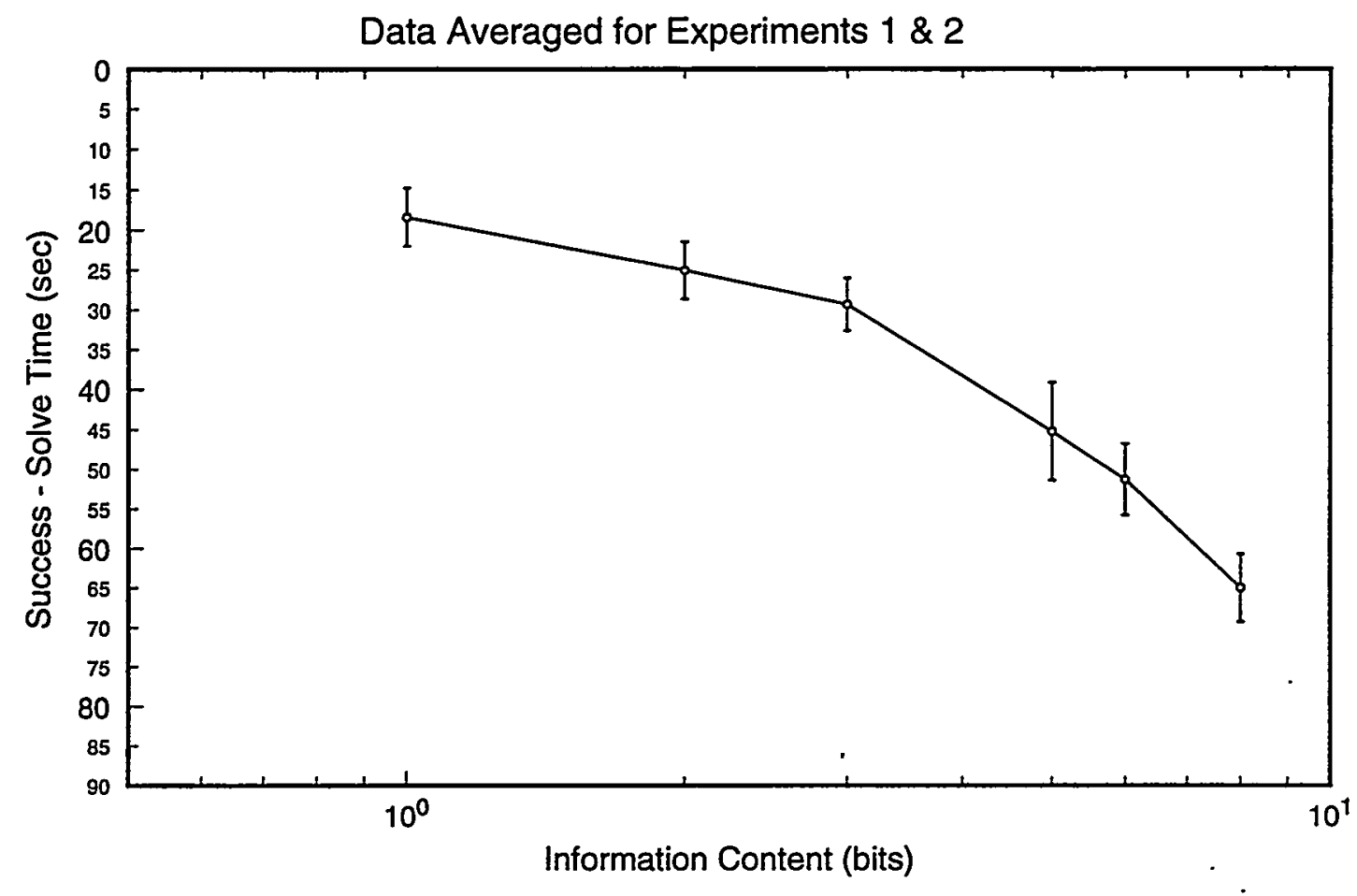


Note: The success, or solve time, plotted on the ordinate axis refers to the average time in seconds required for the research subjects to regain equilibrium control of the reactor during the experimental trials.

Now it is clear that as the information content the subject has to deal with increases, the required time to establish equilibrium also increases. In addition, the threshold value of information content where human reliability breaks down is much more clearly defined. It appears that this threshold occurs near 3 bits of information.

\subsection{Discussion of Experimental Error}

In this section, sources of possible experimental error are suggested. First, the simulation has a characteristic response time whenever a control is moved or a perturbation is performed. For instance, if a valve perturbation is presented the mass flow rate decreases at the characteristic rate. It continues to decrease until the user moves the appropriate controls to fix the perturbation. Once the controls are moved, the system returns to equilibrium at a different characteristic rate depending on exactly how the controls were manipulated. Therefore even though two users may recognize what has gone wrong in the same amount of time they may not return the system to equilibrium in the same amount of time. Since we are using the time to reach equilibrium as a measure of success instead of the time of problem diagnosis, slight random errors occur because the information content is based upon how difficult the perturbations are to diagnose. The size of these errors may be estimated from the standard deviation error bars of Figure 
3-3. They indicate the amount of variability among the subjects in response to identical levels of task information content.

Another source of error may lie in subject training inconsistencies. If a group of subjects were trained in a biased way, their results would be systematically better or worse than the rest of the subjects, depending upon the circumstances. The training done for this work, however, was done with great concern for consistency in order to diminish these types of systematic errors. 


\section{Chapter 4}

\section{Discussion}

The significance of the results is discussed in this section. A foundation is also laid for extending the findings beyond the scope of this work.

The results support the hypothesis of this work. That is, as the information content present in a task increases above a certain threshold value, the task becomes more complex and requires an increasing amount of time to complete. Figure 3-3 indicates this very clearly, however there are some interesting features to note. First, the threshold information value where the success rate begins a notable decline is located at 3 bits of information, as shown in Figure 3-3. An observation of the figure indicates that the experiments did not obtain data at 4 bits of information. Therefore, the actual threshold of success may deviate from the value obtained in this study. Additionally it could be argued that the size of the error bars on the point of 5 bits of information warrants shifting the threshold value even further above 3 bits and closer to 5 bits. The error bars on the point at 5 bits show a large variability in the human response. This may indicate the edge of a threshold, with some subjects still performing well and others performing poorly, being beyond their capability to complete the task successfully. Additional experiments need to be performed in order to determine the value of the success threshold more accurately. However, determining that value was not the principal aim of 
this work. Although the exact value of the threshold is of fundamental importance, the main contribution of the work reported here is that the success of an individual in completing a task declines monotonically as the information content present in the task increases above a certain threshold value.

The final goal of this work is to lay a foundation for extending the reported results beyond the nuclear power plant model. We believe that since the model presented here conveys information in a consistent and clearly defined way, it should be possible to extend these results to a more fundamental level. In fact, any model that allows system complexity to be specifically defined should offer results similar to the trends reported here. Specifically, human reliability should decrease as the task information content increases above a certain threshold value. Additionally, the threshold value of information content (in bits) where human reliability breaks down should be consistent across all system models. As is stated earlier, more work must be done in order to measure this threshold more precisely, but regardless of the system model used, consistent results must be found to verify the validity of this report. 


\section{Chapter 5}

\section{Conclusions}

Two main conclusions may be drawn from this work. The first is that human reliability depends upon task information content. Specifically, as the information content contained in a task increases, the capacity of a human to deal successfully with the task decreases monotonically. Here the definition of total success is the ability to complete the task at hand fully and correctly. Furthermore, there exists a value of information content below which a human can deal with the task successfully, but above which the success of an individual decreases. These ideas should be generalizable to any model where system complexity can be clearly and consistently defined. 


\section{References}

[1] Sanders MS, McCormick EJ. Human Factors in Engineering and Design (Seventh Edition). McGraw-Hill, Inc. New York, 1993.

[2] Golay MW, Seong PH, Manno VP. A measure of system complexity and its relationship to diagnosis. Submitted to Internat. J. of General Systems (1988).

[3] Hick W. On the rate of gain of information. Quarterly Journal of Experimental Psychology, 4 (1952), 11-26.

[4] Hyman R. Stimulus information as a determinant of reaction time. Journal of Experimental Psychology, 45 (1953), 423-432.

[5] Seong PH, Manno VP, Golay MW. Application of a power plant simplification methodology: The example of the condensate feedwater system. Nuclear Engineering and Design, 110 (1988) 33-46.

[6] Rouse WB, Rouse SH. Measures of complexity of fault diagnosis tasks. IEEE Trans. On Systems Man and Cybernetics, SMC-9 (1979), 720-727.

[7] Mackinnon AJ, Wearing AJ. Complexity and decision making. Behavioral Science, 25 (1980), 285-296.

[8] Henry AF. Nuclear Reactor Analysis. The MIT Press. Cambridge, Massachusetts, 1975.

[9] Todreas NE, Kazimi MS. Nuclear Systems (1. Thermal Hydraulic Fundamentals). Hemisphere Pub. Corp. New York, 1990. 


\section{Appendix A}

Simulation Equations

This section conveys the equations used in creating the computer simulation. The mathematics involved may be separated into two parts, reactor physics and thermal hydraulics. Referring to Figure 2-1, we see that the simulation consists of a reactor core and two steam generators connected in parallel. The reactor core is governed by reactor physics equations which are described in Section A of this appendix. The core acts essentially as a heat source, heating the coolant fluid as it passes through. The fluid is then divided into two steam generators where the heat is removed as explained by the thermal hydraulic equations located in Section B. The two sets of equations are coupled through temperature feedback effects. The following sub-sections explain these matters further.

\section{A. Reactor Physics Equations}

The following reactor physics equations describe the neutron population in the core over time. The variable that has the most direct effect on the neutron population is the reactivity, $\rho$, which is in part controlled by the reactor operator through the use of the control rods. Equation A.1 defines the total reactivity in the core as 


$$
\rho=-\rho_{o} \delta\left(T_{\text {core }}-T_{o}\right)+\rho_{\text {worth }}\left(\frac{z}{z_{o}}-1\right)
$$

The first term in the equation describes the temperature feedback effect on the reactivity, where $\delta$ is the coupling constant $(0.01 \$ / \mathrm{K})$ and $\rho_{\mathrm{o}}$ is the reference reactivity $(1.0 \$)$. This term couples the thermal hydraulics to the reactor physics. The amount of feedback is dependent upon the difference between the average core temperature and the reference core temperature $T_{\circ}(603.0 \mathrm{~K})$. The second term in A.1 is the independent contribution where the user manually changes the control rod height, $z$, within the core relative to the reference height, $z_{0}$, of $50.0 \mathrm{~cm}$. The control rods are defined to have a total reactivity worth, $\rho_{\text {worth }}$ of $0.25 \$$.

The above reactivity contributes directly to equation A.2, the point kinetics equation

$$
v \frac{\partial n}{\partial t}=\frac{\partial \Phi}{\partial t}=\frac{\Phi}{\Lambda}(\rho-\beta)+v \lambda N+\text { Source }
$$

Here, the neutron concentration, $n$, or more generally the neutron flux, $\Phi$, within the core depends upon the difference between $\rho$ and $\beta$ (0.0075). The last term in equation A.2 corresponds to a source of neutrons that may be added at random to the core to simulate the source perturbation that is introduced during some of the experimental trials. The 
neutron flux also depends on certain constants, namely the neutron lifetime $\Lambda(0.0001$ $\mathrm{sec})$, thermal velocity $v(220000.0 \mathrm{~cm} / \mathrm{sec})$, and precursor decay constant $\lambda\left(0.08 \mathrm{sec}^{-1}\right)$, with the precursor concentration $\mathrm{N}$ given by the relationship

$$
\frac{d N}{d t}=-\lambda N+\frac{\beta \Phi}{v \Lambda}
$$

Finally, the core power is calculated simply by scaling the neutron flux within the core with a reference flux, $\Phi_{\circ}\left(1.0 \mathrm{E} 13 \mathrm{n} / \mathrm{cm}^{2} / \mathrm{sec}\right)$, and reference power, $Q_{0}(282.0 \mathrm{MW})$ as

$$
Q_{\text {core }}=Q_{o}\left(\frac{\Phi}{\Phi_{o}}\right)
$$

As we will see in the following section, the core power, $Q_{c o r e}$ is used to couple reactor physics to the thermal hydraulic systems, so in combination with the temperature feedback coupling as described above, we have a doubly coupled system.

\section{B. Thermal Hydraulics Equations}

The thermal hydraulics, which govern heat transfer and coolant flow rate, are coupled 
to the reactor physics through the existence of the core power level in the following equation

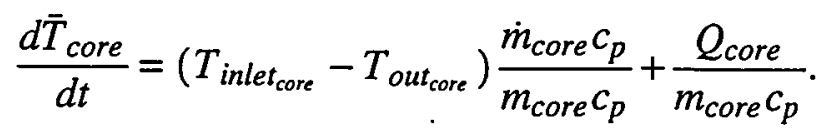

The power therefore contributes to determine the average core temperature, which in turn couples with equation A.1 to form the doubly coupled system discussed earlier. Equation A.5 also contains two constants, the specific heat of water, $c_{p}(4700.0 \mathrm{~J} / \mathrm{kg} / \mathrm{K})$, and the mass of fluid in the core at any instant, $\mathrm{m}_{\text {core }}(3500.0 \mathrm{~kg})$. The inlet and outlet coolant temperatures of the core are defined repectively as

$$
T_{\text {inlet }_{\text {core }}}=\frac{1}{\dot{m}_{\text {core }}}\left(\dot{m}_{1} T_{\text {out }}+\dot{m}_{2} T_{\text {out }} \cdot\right.
$$

and

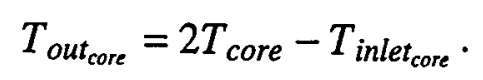

where the subscripts SG1 and SG2 refer to steam generator 1 and 2, respectively. The mass flow rates in equations A.5-A.7 (signified by the letter $m$ with a dot above) refer to the mass flow rate of coolant (in this case water) flowing through the designated area. For instance, the mass flow rate of fluid through each steam generator is defined as 


$$
\frac{d \dot{m}_{1}}{d t}=\frac{1}{2} \frac{A_{\text {flow }_{1}}^{2}}{V_{\text {system }}}\left[\Delta p_{\text {pump }_{1}}-4 k_{1} \frac{\dot{m}_{1}^{2}}{\mathrm{P}_{o} A_{\text {flow }_{1}}^{2}}-h g \Delta \mathrm{P}_{1}\right]
$$

and

$$
\frac{d \dot{m}_{2}}{d t}=\frac{1}{2} \frac{A_{\text {flow }}^{2}}{V_{\text {system }}}\left[\Delta p_{\text {pump }_{2}}-4 k_{2} \frac{\dot{m_{2}^{2}}}{\mathrm{P}_{o} A_{\text {flow }}^{2}}-h g \Delta \mathrm{P}_{2}\right]
$$

where the $\Delta \mathrm{P}$ terms represent buoyancy forces that push the fluid through the respective steam generator loops. The buoyancy terms are defined by

$$
\Delta \mathrm{P}_{1}=-\mathrm{P}_{o} \alpha\left(T_{\text {out }_{\text {core }}}-T_{\text {out }}\right)
$$

and

$$
\Delta \mathrm{P}_{2}=-\mathrm{P}_{o} \alpha\left(T_{\text {out }}-T_{\text {coute }}-\right.
$$

The mass flow rate through the core is calculated simply by adding the mass flow rates through each steam generator together as follows

$$
\dot{m}_{\text {core }}=\dot{m}_{1}+\dot{m}_{2}
$$

Equations A.8 and A.9 contain two independent variables, $\Delta \mathrm{p}_{\text {pump }}$ and $k$. When the user changes the pump pressure on the interface, $\Delta \mathrm{p}_{\text {pump }}$ is the variable that is actually 
being modified. When the user closes the valves, they are actually increasing the value of $k$. When a valve perturbation occurs, the value of $k$ is set automatically to 10 and the user is prevented from moving the valves in this situation.

Equations A.8-A.11 also contain many constant variables whose meanings are not obvious. For instance, A.8 and A.9 contain the cross sectional flow areas through each steam generator, as designated by $\mathrm{A}_{\text {flow }}\left(0.4 \mathrm{~m}^{2}\right.$ in each steam generator). The coolant system total volume is designated by $\mathrm{V}_{\text {system }}$, and has a value of $250.0 \mathrm{~m}^{3}$. The height differential between the core and the steam generators is defined by the letter $h$, and has a value of $15.0 \mathrm{~m}$. Gravity (in $\mathrm{m} / \mathrm{s}^{2}$ ) is represented by $g$ in A.8 and A.9. The coefficient of expansion for water, $\alpha$, has a value of $0.11 / \mathrm{K}$, and the density of water, $P_{o}$, is $1000 \mathrm{~kg} / \mathrm{m}^{3}$ in A.10 and A.11.

The final variables to be discussed are the outlet temperatures of the fluid exiting each steam generator, defined by

$$
T_{\text {out }_{\text {sG }}}=T_{\text {cold }}+\left(T_{\text {out }_{\text {core }}}-T_{\text {cold }_{1}}\right) e^{\frac{U A_{1}}{n_{1} c_{p}}},
$$

and

$$
T_{\text {out } t_{\text {SC2 }}}=T_{\text {cold }}+\left(T_{\text {out }_{\text {core }}}-T_{\text {cold }_{2}}\right) e^{-\frac{U A_{2}}{m i 2_{2} c_{p}}} .
$$

These variables depend exponentially on the heat exchanger magnitude $U A$ which is controlled directly by the user in these experiments. The important variable in equations A.13 and A.14 is the cold side temperature in each steam generator, $\mathrm{T}_{\text {cold }}$. For the work 
reported here, $\mathrm{T}_{\text {cold }}$ has an initial value of $585.0 \mathrm{~K}$ in each steam generator. However, in the event of a steam generator leak perturbation the value of $T_{\text {cold }}$ is reduced 100 degrees to $485.0 \mathrm{~K}$ in the steam generator where the leak occurred. 


\section{Appendix B \\ Experimental Data}

The following tables show the entirety of data points collected from the two experiments. The column headings indicate the expected number of interrogations needed to sufficiently identify the state of the perturbed system. The numbers below indicate the times (in seconds) required by the various research subjects to successfully identify the perturbations that occurred in each of the experimental trials. The data are presented for both sets of experiments with the numbers in the tables being in no particular order.

*Note: The column containing numbers preceded by an asterisk should be ignored. The presence of these numbers is an artefact of the spreadsheet program used to generate this table. They are automatically included and cannot be removed. 
Table B-1

Complete Listing of Experimental Data from Set \#1

\begin{tabular}{|c|c|c|c|c|c|c|c|c|c|}
\hline & & \multicolumn{8}{|c|}{ Data From Experiment Set \#1 } \\
\hline & & \multicolumn{8}{|c|}{ Expected Number of Interrogations Needed To Determine True State of System } \\
\hline & & 1 & $2 \mid$ & 3 & 4 & \begin{tabular}{l|l}
5 & -19 \\
\end{tabular} & 6 & 7 & 8 \\
\hline \multirow{22}{*}{$\begin{array}{l}\text { The numbers } \\
\text { in the various } \\
\text { columns at } \\
\text { right indicate } \\
\text { time (sec) } \\
\text { required to } \\
\text { achieve } \\
\text { success. }\end{array}$} & $* 1$ & 16 & 28 & & & 50 & & & 65 \\
\hline & $* 2$ & 15 & 27 & & & 45 & & & 73 \\
\hline & *3 & 26 & 27 & & & 47 & & & 65 \\
\hline & $*_{4}$ & 27 & 30 & & & 55 & & & 57 \\
\hline & $* 5$ & 14 & 18 & & & 33 & & & 56 \\
\hline & $* 6$ & 14 & 19 & & & 54 & & & 66 \\
\hline & $* 7$ & 19 & 23 & & & 52 & & & 77 \\
\hline & $* 8$ & 17 & 26 & & & 38 & & & 65 \\
\hline & $* 9$ & 17 & 25 & & & 35 & & & 68 \\
\hline & $* 10$ & 17 & 22 & & & 36 & & & 63 \\
\hline & $* 11$ & 16 & 33 & & & 36 & & & 66 \\
\hline & $* 12$ & 16 & 30 & & & 45 & & & 66 \\
\hline & $* 13$ & 17 & 28 & & & 49 & & & 65 \\
\hline & ${ }^{* 14}$ & & 26 & & & 51 & & & 64 \\
\hline & ${ }^{*} 15$ & & 26 & & & 55 & & & 61 \\
\hline & $* 16$ & & 27 & & & 47 & & & 63 \\
\hline & $* 17$ & & 31 & & & 46 & & & 67 \\
\hline & ${ }^{*} 18$ & & 27 & & & 35 & & & 65 \\
\hline & $* 19$ & & 30 & & & 47 & & & 65 \\
\hline & $* 20$ & & & & & 52 & & & 64 \\
\hline & $* 21$ & & & & & 57 & & & 65 \\
\hline & $* 22$ & & & & & 50 & & & \\
\hline
\end{tabular}


Table B-2

Complete Listing of Experimental Data from Set \#2

\begin{tabular}{|c|c|c|c|c|c|c|c|c|c|}
\hline & & \multicolumn{8}{|c|}{ Data From Experiment Set $\# 2$} \\
\hline & & \multicolumn{8}{|c|}{ Expected Number of Interrogations Needed To Determine True State of System } \\
\hline & & 1 & 2 & 3 & 4 & \begin{tabular}{l|l}
5 & 1 \\
\end{tabular} & 6 & 7 & 8 \\
\hline \multirow{25}{*}{$\begin{array}{l}\text { The numbers } \\
\text { in the various } \\
\text { columns at } \\
\text { right indicate } \\
\text { time (sec) } \\
\text { required to } \\
\text { achieve } \\
\text { success. }\end{array}$} & $* 1$ & 17 & 25 & 24 & & 39 & 65 & & \\
\hline & *2 & 21 & 18 & 26 & & 42 & 46 & & \\
\hline & *3 & 22 & 24 & 31 & & 49 & 58 & & \\
\hline & $* 4$ & 18 & 24 & 34 & & 42 & 50 & & \\
\hline & $* 5$ & 18 & 19 & 311 & & 45 & 41 & & \\
\hline & *6 & 17 & 26 & 29 & & 40 & 52 & & \\
\hline & $* 7$ & 23 & 29 & 33 & & 44 & 46 & & $\circ$ \\
\hline & $* 8$ & & 21 & 33 & & 46 & 51 & & \\
\hline & $* 9$ & & 27 & 28 & & 42 & 53 & & \\
\hline & $* 10$ & & 27 & 35 & & 46 & 51 & & \\
\hline & $* 11$ & & 21 & 28 & & 45 & 52 & & \\
\hline & $* 12$ & & 21 & 23 & & 42 & 51 & & \\
\hline & $* 13$ & & 25 & 27 & & 47 & 50 & & \\
\hline & $* 14$ & & 24 & 28 & & & 50 & & \\
\hline & $* 15$ & & 23 & 26 & & & 50 & & \\
\hline & $* 16$ & & 21 & 26 & & & 52 & & \\
\hline & $* 17$ & & 23 & 25 & & & 51 & & \\
\hline & $* 18$ & & 25 & 29 & & & 51 & & \\
\hline & *19 & & 28 & 29 & & & 51 & & \\
\hline & $* 20$ & & 26 & 30 & & & 55 & & \\
\hline & $* 21$ & & 25 & 32 & & & 51 & & \\
\hline & $* 22$ & & & 30 & & & & & \\
\hline & $* 23$ & & & 33 & & & & & \\
\hline & $* 24$ & & & 35 & & & & & \\
\hline & *25 & & & 30 & & & & & \\
\hline
\end{tabular}

